\title{
Comparative in Vitro Myocardial Inotropic Effects and in Vivo Hemodynamic Effects of Forskolin and Isoproterenol in Young Lambs
}

\author{
ROBERT E. SHADDY, CHUN MAK, AND MICHAEL R. BRISTOW \\ Departments of Pediatric's and Medicine, University of Utah School of Medicine, Salt Lake City, Utah 84132
}

\begin{abstract}
Previous studies have shown a decreased responsiveness of young lambs to isoproterenol, a $\beta$-adrenergic agonist, when compared to older lambs. To see if this decreased responsiveness of immature lambs is secondary to an abnormality of the $\beta$-adrenergic receptor/ adenylate cyclase complex, we compared the effects of isoproterenol to forskolin, a direct activator of the catalytic subunit of adenylate cyclase. In isometrically contracting right ventricular trabeculae from five lambs (5-13 d old), the maximal developed tension with isoproterenol $(875 \pm$ $84 \mathrm{mg}$, mean $\pm \mathrm{SD})$ and forskolin $(704 \pm 189 \mathrm{mg})$ was similar. However, the median effective dose for isoproterenol $\left(5.3 \pm 3.4 \times 10^{-7} \mathrm{M}\right)$ was significantly less than the minimal median effective dose for forskolin $(2.5 \pm 1.3 \times$ $10^{-6} \mathrm{M}$ ) indicating a lesser sensitivity to forskolin. In eight conscious resting lambs (4-13 d old) we measured the hemodynamic response to graded infusions of isoproterenol and forskolin. At maximal dosage, the increase in cardiac output was significantly greater with isoproterenol $(+130 \%)$ than forskolin $(+55 \%)$. Heart rate also increased more with isoproterenol than forskolin. These data show that direct stimulation of adenylate cyclase in young lambs does not provide better inotropic or chronotropic responses than $\beta$-adrenergic stimulation with isoproterenol. This suggests that the decreased $\beta$-adrenergic responsiveness in newborn lambs is secondary to abnormalities that exist beyond the level of the $\beta$-adrenergic receptor/adenylate cyclase complex. (Pediatr Res 25:580-584)
\end{abstract}

Previous studies have shown that young lambs, when compared to older lambs, have a limited ability to increase cardiac output (1) and contractility (2) in response to inotropic stimulation with $\beta$-adrenergic agonists, such as isoproterenol. The reason for this decreased responsiveness to $\beta$-adrenergic stimulation is unclear. It has been suggested that the newborn lamb myocardium is operating at a high resting $\beta$-adrenergic state with little reserve to increase cardiac output in response to further $\beta$ adrenergic stimulation (2). However, Friedman (3) showed the $\beta$-receptor sensitivity to catecholamines to be similar in adult and fetal myocardium, supporting the notion that sympathetic innervation is incomplete or functionally immature in the heart of the fetus or early newborn. Because of similarities in $\beta$ adrenergic receptor density and affinity, and in adenylate cyclase activity between fetal and adult myocardium, it has also been suggested that this decreased responsiveness to $\beta$-adrenergic stimulation is due to developmental differences that occur at a level

Reccived July 22, 1988; accepted January 12, 1989.

Correspondence Robert E. Shaddy, M.D.. Department of Pediatrics, University of Utah School of Medicine. 50 North Medical Drive, Salt Lake City, UT 84132. beyond the $\beta$-adrenergic receptor/adenylate cyclase complex (4, 5).

Forskolin is a diterpene derivative with the ability to rapidly and reversibly activate the intracellular catalytic subunit of adenylate cyclase without interacting with the guanyl nucleotide regulatory subunit, thus stimulating cAMP production directly $(6,7)$. Forskolin stimulates adenylate cyclase to a greater extent than isoproterenol in both normal human hearts and in hearts from patients with congestive heart failure (8). Inasmuch as hearts from patients with congestive heart failure have a reduction in $\beta$-adrenergic receptor density and/or $\beta$-adrenergic receptor/adenylate cyclase coupling (9), the advantage of forskolin over isoproterenol lies in its ability to stimulate adenylate cyclase directly and not depend on $\beta$-adrenergic receptor density, or coupling to adenylate cyclase.

If the etiology of the decreased responsiveness to $\beta$-adrenergic stimulation is due to an abnormality of $\beta$-adrenergic receptor density or $\beta$-adrenergic receptor/adenylate cyclase coupling, then forskolin would produce relatively greater effects in immature lambs and might be a better inotropic and chronotropic agent to use in the newborn period. The purpose of this study was to examine the in vitro myocardial inotropic effects and in vivo hemodynamic effects of forskolin in young lambs and to compare these effects to isoproterenol.

\section{MATERIALS AND METHODS}

In vitro studies. We examined the effects of forskolin and isoproterenol on the isolated right ventricular trabeculae of five young lambs, age 5 to $13 \mathrm{~d}$ old (mean $10 \mathrm{~d}$ ). The lambs were anesthetized with intravenous ketamine, $20 \mathrm{mg} / \mathrm{kg}$. The animals were then intubated, and the hearts immediately excised and placed into ice-cold, oxygenated physiologic salt solution. Eight trabeculae from the free wall of the right ventricle were removed from each heart. Trabeculae of approximately $1 \mathrm{~mm}$ in diameter were used, and were removed from the heart at a uniform size of approximately 6-7 $\mathrm{mm}$ in length. Each muscle was then attached to a force displacement transducer by means of a gold chain attached to plastic clips and placed in eight separate $80 \mathrm{ml}$ tissue baths at a temperature of $37^{\circ} \mathrm{C}$ containing physiologic salt solution (in mM, $118 \mathrm{NaCl}, 4.0 \mathrm{KCl}, 1.2 \mathrm{MgSO}_{4}, 24.0 \mathrm{NaHCO}_{2}$, 1.2 $\mathrm{Na}_{2} \mathrm{PO}_{4}, 2.5 \mathrm{CaCl}_{2}, 5.0$ dextrose). Each muscle was gradually stretched to attain maximal resting tension. The degree of stretch (preload tension) was approximately $1.0 \mathrm{~g}$ in all cases. Actively developed tension was calculated as the difference between total developed tension during pharmacologic intervention and resting tension. Isometric contraction was generated by field stimulation through platinum electrodes placed parallel to the long axis of the muscle that delivered a $3 \mathrm{~ms}$ square-wave impulse at a rate of $1.0 \mathrm{~Hz}$. The tissue was equilibrated in the physiologic salt solution for $90 \mathrm{~min}$. All recordings were made on an eightchannel recorder with light-sensitive paper. Four of the trabecu- 
lae were given forskolin and four were given isoproterenol. Increases in concentration of the agonists between $10^{-9}$ and $10^{-4}$ $\mathrm{M}$ were added in a cumulative fashion. Isoproterenol doses were increased every $2 \mathrm{~min}$. Forskolin doses were increased every 8 min since preliminary studies had demonstrated a slower onset of action.

In vivo studies. We examined the hemodynamic response to graded infusions of isoproterenol and forskolin in eight conscious resting lambs, age 4-13 d old (mean 6 days). On the day before the study, the lambs were anesthetized with ketamine, $10 \mathrm{mg} / \mathrm{kg}$ intramuscularly. We then advanced polyvinyl catheters from a peripheral artery and vein into the aorta and inferior vena cava for measurement of aortic pressure and infusion of medications, respectively. We inserted a $5 \mathrm{~F}$ balloon-tip thermodilution catheter from the internal jugular vein into the pulmonary artery. During insertion, we obtained $\mathrm{Hb}$ oxygen saturations in the right atrium, right ventricle, and pulmonary artery to rule out any left to right shunting. After at least $1 \mathrm{~d}$ of recovery, the lambs were weighed, blindfolded, placed erect in a sling, and studied in a room with temperature controlled at $22-25^{\circ} \mathrm{C}$. We made continuous measurements of aortic pressure, pulmonary artery pressure, heart rate, and the ECG and recorded them on a Honeywell multiple-channel recorder (Honeywell Inc., Denver, CO) with light-sensitive paper. We measured cardiac output by the thermodilution method and measured pulmonary capillary wedge pressures by intermittent balloon inflation of the pulmonary artery catheter.

We performed two protocols on 2 separate $\mathrm{d}$. On $1 \mathrm{~d}$ we gave a continuous intravenous infusion of forskolin in an ascending dose fashion from $1-100 \mathrm{nmol} / \mathrm{kg} / \mathrm{min}(0.4-40 \mu \mathrm{g} / \mathrm{kg} / \mathrm{min})$. On another day we gave a continuous intravenous infusion of isoproterenol in an ascending dose fashion from $0.1-20 \mathrm{nmol} / \mathrm{kg} /$ $\min (0.025-5 \mu \mathrm{g} / \mathrm{kg} / \mathrm{min})$. In all studies except one, forskolin was administered first, followed by isoproterenol. The number of days between the studies was $1 \mathrm{~d}$ in 7 of the lambs, and $3 \mathrm{~d}$ in one lamb. Forskolin was dissolved in anhydrous DMSO and further diluted to the desired concentration with sterile water.
Both drugs were infused at each concentration at a rate of 0.15 $\mathrm{ml} / \mathrm{min}$. We obtained hemodynamic measurements at each dosage level of each drug.

DMSO was administered to four of the lambs as a vehicle, and no significant changes were noted in any of the measured hemodynamic parameters.

Statistics. Statistical comparisons between means were compared using the paired and unpaired Student's $t$ test with Bonferroni correction for multiple samples. Values with $p<0.05$ were considered statistically significant. All values are expressed as mean $\pm \mathrm{SD}$.

\section{RESULTS}

In vitro studies of the right ventricular trabeculae from five young lambs demonstrated no significant difference in the maximal-developed tension between trabeculae treated with isoproterenol $(875 \pm 84 \mathrm{mg})$ or forskolin $(704 \pm 189 \mathrm{mg})$. However, the $\mathrm{ED}_{50}$ was significantly less for isoproterenol, suggesting a lesser potency for forskolin (Fig. 1). With forskolin a plateau of maximal-developed tension was not attained at a dose of $1 \times$ $10^{-5} \mathrm{M}$ and further increases in dosage resulted in excessive spontaneous contractions and a persistent increase in beat frequency beyond $1.0 \mathrm{~Hz}$. Curves demonstrating the effect of agonist on actively developed tension were developed using a nonlinear least squares curve-fitting program. Curves were modeled to a four-parameter logistic equation after the method of DeLean et al. (10), to find the best fit of the sigmoidal curve. For the purpose of curve fitting, a final point on the forskolin doseresponse curve $\left(1 \times 10^{-4} \mathrm{M}\right)$ was added at a tension similar to that attained at $1 \times 10^{-5} \mathrm{M}$. Thus the calculated $\mathrm{ED}_{50}$ for forskolin is a minimum $\mathrm{ED}_{50}$ because a true maximal tension could not be attained. However, using this method, the calculated minimal $\mathrm{ED}_{50}$ for forskolin $\left(2.5 \pm 1.3 \times^{-6} \mathrm{M}\right)$ was approximately 4.7 times more than the $\mathrm{ED}_{50}$ for isoproterenol $\left(5.3 \pm 3.4 \times 10^{-7}\right.$ $\mathrm{M})$, indicating the lesser potency of forskolin. Inasmuch as this

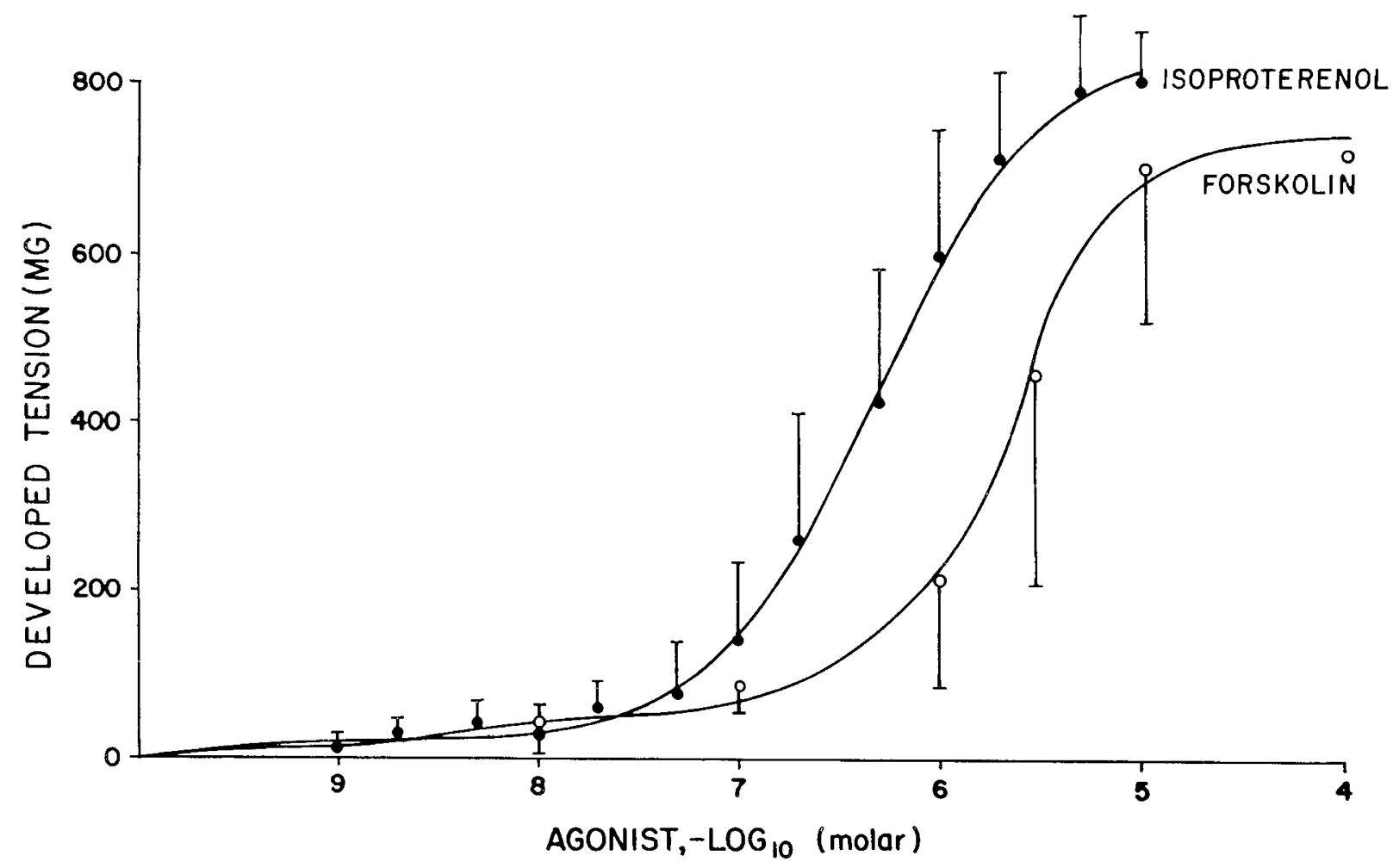

Fig. 1. Dose-response curves for isoproterenol (closed circles) and forskolin (open circles) in isolated right ventricular trabeculae from lambs. Each point is the mean $\pm \mathrm{SD}$ of four muscle bath experiments from five lambs. ED50 are $5.3 \pm 3.4 \times 10^{-7} \mathrm{M}$ (isoproterenol) and $2.5 \pm 1.3 \times 10^{-6}$ $\mathrm{M}$ (forskolin) 
is a minimal $E D_{50}$, it is possible that the true potency of forskolin compared to isoproterenol may be even less. There was no significant difference between the slopes of the two curves.

At a stimulation frequency of $1.0 \mathrm{~Hz}$, occasional spontaneous contractions of the trabeculae occurred at the higher dosages of both drugs. Alterations in rate of contraction can directly affect contractile state $(11,12)$. In two studies, in an attempt to obviate this problem, we increased the frequency of the field stimulation to $2.0 \mathrm{~Hz}$, and the occurrence of the spontaneous contractions increased, so this was abandoned. We therefore performed studies in which maximal-developed resting tension was measured in eight right ventricular trabeculae of three young lambs over the range of contraction frequency seen in this study. There was no significant difference in resting tensions between frequencies of $1.0 \mathrm{~Hz}(634 \pm 477 \mathrm{mg}), 1.5 \mathrm{~Hz}(616 \pm 449 \mathrm{mg})$, and $2.0 \mathrm{~Hz}$ $(605 \pm 447 \mathrm{mg})$.

In vivo hemodynamic effects of forskolin and isoproterenol in eight young lambs also demonstrated a lesser responsiveness to forskolin than isoproterenol. Cardiac output increased significantly $(+55 \%)$ in the lambs at the maximal forskolin dosage infusion. However, the increase in cardiac output at maximal isoproterenol dosage $(+130 \%)$ was significantly greater (Fig. 2$)$. The variability of the cardiac output measurements in the lambs in this study is normal and comparable to previous studies (13, 14). Similarly, heart rate increased markedly during forskolin infusion, although this was significantly less than during isoproterenol infusion (Fig. 3). There were no significant changes in aortic, pulmonary artery, or pulmonary capillary wedge pressures during infusion of isoproterenol or forskolin (Table I). Inasmuch as cardiac output increased while aortic and pulmonary artery pressures did not change with administration of either drug, systemic, and pulmonary vascular resistances decreased proportionately during drug infusions, although the decrease in pulmonary vascular resistance was not significant after forskolin. Inasmuch as the studies were performed on consecutive days and the lambs were allowed a minimum of $1 \mathrm{~d}$ to rest between studies, the ages of the lambs and order of administration of the drugs should have no effect on the measured responses.

\section{DISCUSSION}

Inasmuch as some studies have shown that the immature heart has decreased responsiveness to $\beta$-adrenergic receptor stimulation when compared to adult hearts $(1,2)$, drugs that have inotropic and chronotropic actions through mechanisms separate from the $\beta$-adrenergic receptor may have advantages in this age group. The purpose of this study was to examine the in vitro inotropic and in vivo hemodynamic effects of forskolin, a direct activator of the catalytic subunit of adenylate cyclase. Forskolin is a diterpene derivative of the plant Coleus forskohlii. Forskolin has positive inotropic properties and activates adenylate cyclase in isolated heart tissue from rats, guinea pigs, and rabbits (15). It also has positive inotropic and chronotropic actions as well as blood pressure-lowering properties in pig, cat, and dog hearts (16). In open-chest dogs, forskolin increases $\mathrm{dP} / \mathrm{dt}$ and cardiac output, and decreases peripheral vascular resistance and left ventricular end-diastolic pressure (8). Preliminary work in human adults has shown similar hemodynamic effects (17).

In this study forskolin caused maximal-developed tension similar to isoproterenol in the isolated right ventricular trabeculae of young lambs. Although a true maximal-developed tension was not obtained with forskolin in this study, at concentrations comparable to or more than isoproterenol the actively developed tension was no more than that attained by isoproterenol. In fact, the greater $\mathrm{ED}_{50}$ for forskolin indicates that it has a lower potency than isoproterenol in the immature lamb myocardium. A recent study using isolated right ventricular papillary muscles showed a significantly greater degree of maximal rate of tension development with forskolin than isoproterenol in newborn (1-2 d old), when compared to immature (14-16 d old), and adult (6-7 mo old) rabbits (18). The discrepancy with the present study may reflect species differences, or the fact that the newborn lambs (4$13 \mathrm{~d}$ old) in the present study were older and perhaps more mature than the newborn rabbits (1-2 d old) in the previous study.

Some spontaneous contractions were noted with both isoproterenol and forskolin in this study. In situations where sponta-

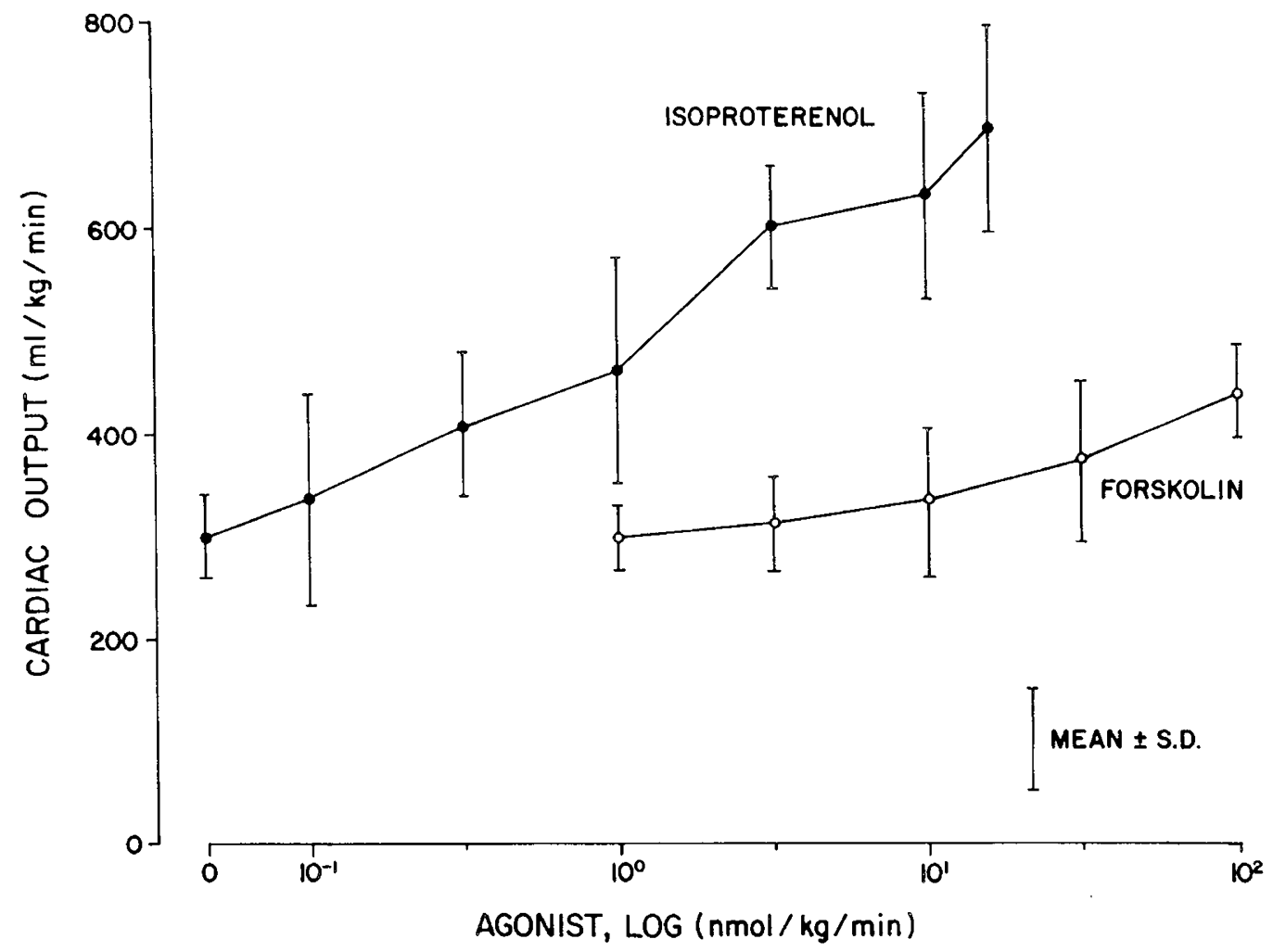

Fig. 2. Response of cardiac output to isoproterenol (Closed circles) and forskolin (open circles) in eight resting, conscious lambs. Points are mean $\pm \mathrm{SD}$. 
ISOPROTERENOL

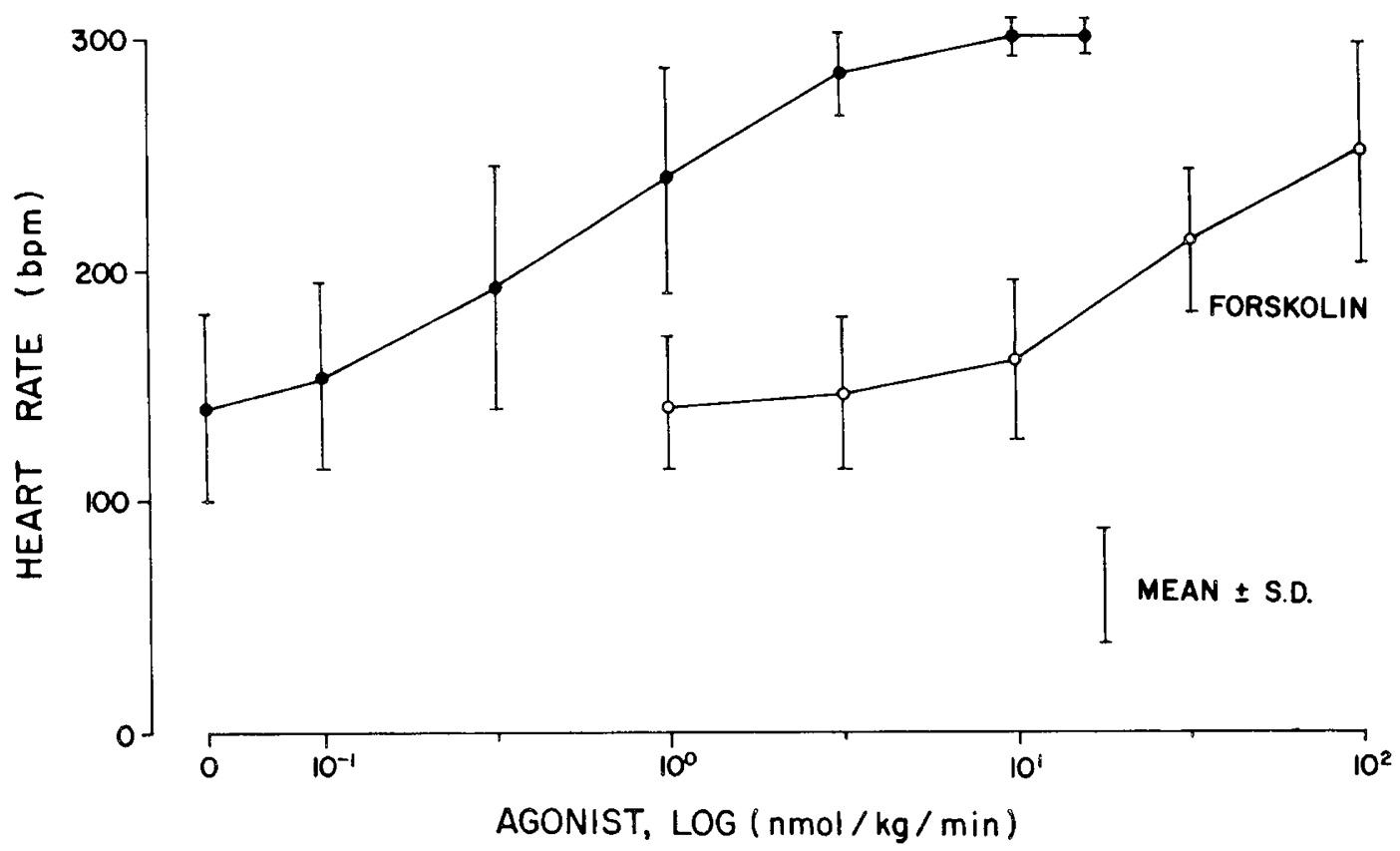
$\mathrm{SD}$

Fig. 3. Response of heart rate to isoproterenol (closed circles) and forskolin (open circles) in eight resting, conscious lambs. Points are mean \pm

Table I. Pressure and resistance responses to maximal doses of isoproterenol and forskolin infusion $(n=8)$

\begin{tabular}{|c|c|c|c|c|c|}
\hline & $\begin{array}{l}\text { Mean } \\
\text { aortic } \\
\text { pressure } \\
(\mathrm{mm} \mathrm{Hg})\end{array}$ & $\begin{array}{c}\text { Mean } \\
\text { pulmonary } \\
\text { artery } \\
\text { pressure } \\
(\mathrm{mm} \mathrm{Hg})\end{array}$ & $\begin{array}{c}\text { Mean pulmonary } \\
\text { capillary wedge } \\
\text { pressure (mm } \\
\mathrm{Hg})\end{array}$ & $\begin{array}{c}\text { Systemic vascular } \\
\text { resistance } \\
(\mathrm{mm} \mathrm{Hg} / \mathrm{liter} / \mathrm{kg} / \mathrm{min})\end{array}$ & $\begin{array}{c}\text { Pulmonary vascular } \\
\text { resistance } \\
\text { (mm } \mathrm{Hg} / \mathrm{liter} / \mathrm{kg} / \mathrm{min} \text { ) }\end{array}$ \\
\hline Baseline & $65.5 \pm 9.7$ & $15.3 \pm 4.1$ & $5.9 \pm 2.6$ & $225.4 \pm 40.6$ & $51.3 \pm 11.1$ \\
\hline Isoproterenol $(20 \mathrm{nmol} / \mathrm{kg} / \mathrm{min})$ & $59.3 \pm 8.6$ & $17.9 \pm 6.0$ & $6.3 \pm 3.6$ & $88.7 \pm 16.5^{*}$ & $26.3 \pm 6.6^{*}$ \\
\hline Baseline & $74.2 \pm 8.6$ & $17.0 \pm 5.5$ & $4.4 \pm 2.3$ & $246.8 \pm 31.9$ & $57.4 \pm 21.9$ \\
\hline Forskolin $(100 \mathrm{nmol} / \mathrm{kg} / \mathrm{min})$ & $70.1 \pm 15.6$ & $20.6 \pm 7.1$ & $4.6 \pm 1.3$ & $152.7 \pm 40.6^{*}$ & $45.4 \pm 18.0$ \\
\hline
\end{tabular}

* Significantly different from baseline $(p<0.05)$.

neous contractions occurred intermittently such that the rate of contraction was irregular, these data were deleted because of the concerns of post extra-systolic potentiation. However, in the occasional instance at the higher concentrations of both drugs when the rate of spontaneous contraction increased at a constant rate above $1.0 \mathrm{~Hz}$, these data were included. The maximaldeveloped tension during these contractions was not significantly greater than that attained at the stimulated frequency of $1.0 \mathrm{~Hz}$. Also, the fact that in three separate studies the maximal-developed tension achieved at rates of $1.0,1.5$, and $2.0 \mathrm{~Hz}$ was not significantly different suggests that over the narrow range of spontaneous contractions and increased beat frequency that occurred in this study, there was no significant contribution to the actively developed tension with either drug.

In conscious resting lambs forskolin caused a significant increase in cardiac output and heart rate but to a much lesser extent than the increases achieved by infusion of isoproterenol at lower concentrations. In all studies, cardiac output and heart rate increased during forskolin administration, but in two of the animals there was no change in either variable until the last two drug dosages. This blunted increase in cardiac output has also been seen in open-chest dogs, but this was believed to be secondary to a decrease in left atrial mean pressure which occurred to a greater extent with forskolin than isoproterenol (8). In contrast, in the present study we demonstrated no significant difference in mean pulmonary capillary wedge pressure which would suggest there was no significant change in left atrial mean pressures. Previous work had also demonstrated a significant decrease in mean arterial pressure with administration of isoproterenol and forskolin (8). In our study neither of these variables changed significantly, although the marked increase in cardiac output associated with no change in arterial pressure would indicate that forskolin has pulmonary and systemic vasodilating properties, although again to a lesser extent that isoproterenol. Inasmuch as systemic and pulmonary vascular resistances decreased more with isoproterenol than with forskolin, the responses that are seen may reflect greater chronotropic and vasodilating properties of isoproterenol rather than lesser inotropic effects of forskolin.

The reasons why forskolin was not superior to isoproterenol with regards to in vitro inotropic and in vivo hemodynamic responses is not clear, because forskolin produces a much greater stimulation of adenylate cyclase in myocardial membranes than isoproterenol (8). This discrepancy may be secondary to biochemical differences between membrane preparations and intact tissues. The demonstration of a greater in vivo effect on cardiac output, heart rate, and systemic vascular resistance of isoproterenol compared to forskolin was unanticipated. One possible explanation for this is that the doses of forskolin used in this study did not achieve a maximal effect in vivo. It is also possible that the ability of forskolin to cross the myocardial cell membrane limits its effectiveness when compared to the ability of isoproterenol to stimulate the $\beta$-adrenergic receptor on the cell membrane. Thus, higher doses of forskolin may achieve results similar to or greater than those achieved by isoproterenol. Finally, isoproterenol could potentially exert a positive inotropic response by mechanisms other than adenylate cyclase stimula- 
tion, such that this additional effect would be additive with its more traditional cAMP-mediated response.

In conclusion, these data demonstrate that forskolin has positive inotropic and chronotropic effects on the myocardium of young lambs that are similar to, but not as marked as those caused by isoproterenol. Thus direct stimulation of adenylate cyclase in the immature lamb myocardium offers no advantage over indirect stimulation of adenylate cyclase through $\beta$-adrenergic receptor stimulation. This would suggest that the decreased responsiveness of young lambs to the $\beta$-adrenergic receptor agonist, isoproterenol, is secondary to an abnormality beyond the level of the $\beta$-adrenergic receptor/adenylate cyclase complex.

Acknowledgment. The authors thank Alexis House for her assistance in the preparation of this manuscript.

\section{REFERENCES}

1. Shaddy RE, Tyndall MT, Teitel DT, Li C. Rudolph AM 1988 Regulation of cardiac output with controlled heart rate in newborn lambs. Pediatr Res 24:577-582

2. Teitel DT, Sidi D, Chin T, Brett C, Heymann MA, Rudolph AM 1985 Developmental changes in myocardial contractile reserve in the lamb. Pediatr Res 19:948-955

3. Friedman WF 1972 The intrinsic physiologic properties of the developing heart. Prog Cardiovasc Dis 15:87-111

4. Cheng JB, Goldfien A, Cornett LE, Roberts JM 1981 Identification of betaadrenergic receptors using $\left[{ }^{3} \mathrm{H}\right]$ dihydroalprenolol in fetal sheep heart. Pediatr Res 15:1083-1087

5. Rockson SG, Homey CJ, Quinn P, Manders WT, Haber E, Vatner SF 1981 Cellular mechanisms of impaired adrenergic responsiveness in neonatal dogs. $\mathrm{J}$ Clin Invest 67:319-327
6. Seamon KB, Padgett W, Daly JW 1981 Forskolin: Unique diterpene activator of adenylate cyclase in membranes and in intact cells. Proc Natl Acad Sci USA 78:3363-3367

7. Daly JW 1984 Forskolin, adenylate cyclase, and cell physiology: An overview. In: Greengard P, Robison GA, Paoletti R, Nicosia S (eds) Advances in Cyclic Nucleotide and Protein Phosphorylation Research, Vol 17. Raven Press, New York, pp 81-89

8. Bristow MR, Ginsburg R, Strosberg A, Montgomery W, Minobe W 1984 Pharmacology and inotropic potential of forskolin in the human heart. $J$ Clin Invest 74:212-223

9. Bristow MR, Ginsburg R, Minobe W, Cubicciotti RS, Rageman WS, Lurie K, Billingham ME, Harrison DC, Stinson EB 1982 Decreased catecholamine sensitivity and beta-adrenergic-receptor density in failing human hearts. $N$ Engl J Med 307:205-211

10. DeLean A, Munson PJ, Rodbard D 1978 Simultaneous analysis of families of sigmoidal curves: application to bioassay, radiologand assay, and physiological dose-response curves. Am J Physiol 235:E97-E102

11. Anderson PAW, Manring A, Johnson EA 1973 Force-frequency relationship: a basis for a new index of cardiac contractility? Circ Res 33:665-671

12. Anderson PAW, Manring A, Johnson EA 1977 The force of contraction of isolated papillary muscle: a study of the interaction of its determining factors. J Mol Cell Cardiol 9:131-150

13. Klopfenstein HS, Rudolph AM 1978 Postnatal changes in the circulation and responses to volume loading in sheep. Circ Res 42:839-845

14. Sidi D, Kuipers JRG, Heymann MA, Rudolph AM 1982 Recovery of cardiovascular function in newborn lambs after thoracotomy. Pediatr Res 16:705710

15. Metzger H, Lindner E 1981 The positive inotropic-acting forskolin, a potent adenylatecyclase activator. Arzneim Forsch 31:1248-1250

16. Lindner E, Dohadwalla AN, Bhattacharya BK 1978 Positive inotropic and blood pressure lowering activity of a diterpene derivative isolated from Coleus forskohli: forskolin. Arzneim Forsch 28:284-289

17. Linderer T, Biamino G, Bruggeman T, Peslin K, Schroder R 1984 Hemodynamic effects of forskolin, a new drug with combined positive inotropic and vasodilating properties. J Am Coll Cardiol 3:562(abstr)

18. Artman M, Kithas PA, Wike JS, Strada SJ 1988 Inotropic responses change during postnatal maturation in rabbit. Am J Physiol 255:H335-H342

\section{Announcement}

\section{First World Congress in Pediatric Pathology}

The First World Congress in Pediatric Pathology will be held September 19-22, 1989 at the World Trade Center, Rotterdam, The Netherlands. An advanced refresher course in perinatal pathophysiology will take place on September 18, 1989. Tentative topics of the congress include congenital defects (molecular biology, new causes, intervention), pregnancy-induced hypertension and IUGR (pathogenesis, prevention, and intervention), intra-uterine infections (modern techniques), neonatal intensive care (including iatrogenic pathology), cot death (pathogenesis, epidemiology), and pediatric oncology (molecular biology, new techniques). For further information contact ICOG-Congressbureau, Mrs. Joyce Fleten, P.O. Box 841, 3000 AN Rotterdam, The Netherlands. 